OPEN ACCESS

Edited by: Jaime Imitola,

The Ohio State University, United States

Reviewed by:

Sofia Beatriz Lizarraga, University of South Carolina, United States

Thomas M. Durcan, McGill University, Canada

*Correspondence: James J. Fink james.j.fink1@gmail.com; Eric S. Levine eslevine@uchc.edu

Specialty section: This article was submitted to

Pediatric Neurology, a section of the journa

Frontiers in Neurology

Received: 04 December 2017 Accepted: 26 March 2018 Published: 16 April 2018

Citation:

Fink JJ and Levine ES (2018) Uncovering True Cellular Phenotypes: Using Induced Pluripotent Stem

Cell-Derived Neurons to Study Early Insults in Neurodevelopmental Disorders.

Front. Neurol. 9:237. doi: 10.3389/fneur.2018.00237

\section{Uncovering True Cellular Phenotypes: Using Induced Pluripotent Stem Cell-Derived Neurons to Study Early Insults in Neurodevelopmental Disorders}

\author{
James J. Fink ${ }^{*}$ and Eric S. Levine* \\ Department of Neuroscience, University of Connecticut School of Medicine, Farmington, CT, United States
}

Animal models of neurodevelopmental disorders have provided invaluable insights into the molecular-, cellular-, and circuit-level defects associated with a plethora of genetic disruptions. In many cases, these deficits have been linked to changes in disease-relevant behaviors, but very few of these findings have been translated to treatments for human disease. This may be due to significant species differences and the difficulty in modeling disorders that involve deletion or duplication of multiple genes. The identification of primary underlying pathophysiology in these models is confounded by the accumulation of secondary disease phenotypes in the mature nervous system, as well as potential compensatory mechanisms. The discovery of induced pluripotent stem cell technology now provides a tool to accurately model complex genetic neurogenetic disorders. Using this technique, patient-specific cell lines can be generated and differentiated into specific subtypes of neurons that can be used to identify primary cellular and molecular phenotypes. It is clear that impairments in synaptic structure and function are a common pathophysiology across neurodevelopmental disorders, and electrophysiological analysis at the earliest stages of neuronal development is critical for identifying changes in activity and excitability that can contribute to synaptic dysfunction and identify targets for disease-modifying therapies.

Keywords: neurodevelopmental disorders, autism spectrum disorders, electrophysiology, synaptic transmission, induced pluripotent stem cells

\section{INTRODUCTION}

In addition to their prevalence and impact on the individual patient, neurological disorders place a large burden on the world population both in economic impact (1) and emotional toll on families. For these reasons, there is an urgent need to develop effective treatments for managing these devastating disorders. To date, the use of animal models to study how disease-causing genetic mutations lead to cellular, molecular, and circuit-level pathophysiology in the brain has led to many important discoveries and a better understanding of disease mechanisms. However, despite these advancements, the development of effective treatments for a wide-variety of neurological disorders remains elusive.

These shortcomings have often been attributed to species differences, including genetic complexity and/or incomplete modeling of relevant behavioral phenotypes, resulting in potential treatments 
that are promising at early stages in animal models but fail during clinical trials on human subjects. This situation has led to a push for the use of human cells for studying neurological disease pathology and validating therapeutic targets (2, 3). Study of human neurons has generally relied on postmortem tissue, which contains unique biological information but is limited by sample size, especially for rare neurogenetic disorders, and variable sample quality. Alternatively, non-invasive imaging techniques can provide some insight into underlying pathology but lack cellular-level spatial resolution, and the use of aborted fetal brain tissue and human embryonic stem cells are associated with ethical controversies (4-6).

The 2007 discovery that somatic cells from human subjects can be reprogrammed into induced pluripotent stem cells (iPSCs) via the overexpression of a distinct set of transcription factors has provided an entirely new avenue for studying disease pathology in neurogenetic disorders (7). Using this technique, patient-specific cell lines can be differentiated into neurons that can serve as a valuable complement to animal models for identifying primary phenotypes at the cellular and molecular level. These samples can be collected from large patient groups, banked, and widely distributed for studies with greater statistical power.

It is clear from animal models and postmortem studies that impairments in synaptic structure and function are a common pathophysiology across disorders (8-10). These findings highlight the importance of synaptic activity in normal brain function and have identified key molecular targets underlying certain forms of pathology, but in many cases these studies have failed to explain how synaptic dysfunction can lead to different neurological disorders. It is likely that synaptic deficits are often times a secondary phenotype that is a consequence of primary changes to neuronal function and excitability early in development. These primary phenotypes could trigger homeostatic responses in neurons and glia that could then result in further changes to excitability including action potential (AP) firing, synaptic communication, and long-term activity-dependent synaptic plasticity. In fact, a recent review has already proposed a similar theme of pathophysiology in relation to autism spectrum disorder (ASD), which is commonly referred to as a "synaptopathy" (11).

In this review, we explore how iPSC-derived neuron technology will help in identifying primary cellular phenotypes associated with neurogenetic disorders, specifically neurodevelopmental disorders, and how these studies might better inform future investigation into pathophysiology and disease treatments and therapies. In particular, we will focus on the use of electrophysiological analysis of iPSC-derived neurons, as understanding the dynamic function of neurons during disease development will ultimately lead to insight into the behaviors and symptoms associated with these neurological disorders.

\section{MOUSE MODELS OF NEURODEVELOPMENTAL DISORDERS}

Autism spectrum disorder consists of a collection of heterogenous neurodevelopmental disorders characterized by impairments in social interactions, including language development, as well as restricted interests and repetitive behaviors $(12,13)$. The prevalence of ASD has been estimated at 1 in 68 (14), and despite the extensive research on understanding the underlying causes of this disorder, the results have been underwhelming (15). Part of this issue is the heterogeneity, not only of the breadth and severity of symptoms across patients, but of the complex genetic alterations associated with ASD (16-18).

To overcome this, recent efforts have focused on studying syndromic forms of autism including single-gene disorders, such as Rett syndrome, Fragile X syndrome (FXS), tuberous sclerosis complex (TSC), and Angelman syndrome (AS), as well as copy number variations in regions 15q11-q13 (Dup15q), 16p11.2, 22q11.2, and others (19). Knowing the causative genes and genomic regions associated with this group of syndromic ASDs allows a more powerful study of the underlying pathophysiology as compared with idiopathic ASD. These studies strongly suggest that heterogenous synaptic deficits underlie these disorders $(15,20)$. Importantly, animal models based on genes that have been strongly associated with ASD, such as SHANK3 and Neurexin-1 (NRXN1), further support the idea that autism is a disorder of defective synapses (21-23). General findings from these various mouse models are discussed below.

\section{5q11-q13-Associated Disorders: as and Dup15q}

Opposite changes in the chromosome 15q11-q13 region give rise to two disorders associated with autistic phenotypes. Maternal deletion of this region gives rise to AS, a neurodevelopmental disorder characterized by inappropriate laughter, ataxia, and seizures. Some patients also present with autistic features such as developmental delay, intellectual disability, and a lack of language (24). Maternal duplication of this region results in chromosome $15 \mathrm{q}$ duplication syndrome (Dup15q), a disorder in which autism is highly penetrant (25). These disorders result from chromosomal changes specific to the maternal allele because the $15 \mathrm{q} 11-\mathrm{q} 13$ region is subject to regulation by genomic imprinting, an epigenetic process resulting in allele-specific gene expression. In the 15q11-q13 region, several genes are exclusively expressed from one parent allele or the other.

One of these genes, $U B E 3 A$, is imprinted in a cell type-specific manner. In particular, in neurons, $U B E 3 A$ is solely expressed from the maternal allele, due to paternal silencing (26-28). AS is specifically caused by loss of $U B E 3 A$, as point mutations in $U B E 3 A$ are sufficient to cause the disorder, accounting for $\sim 15 \%$ of AS cases (29). UBE3A is an E3 ubiquitin ligase responsible for tagging target proteins for degradation by the proteasome, and some of these targets may be important synaptic proteins. Findings in animal models of these disorders support the dysfunctional synapse hypothesis described earlier (29). For instance, mice lacking maternal $U B E 3 A$ have impaired activity-dependent synaptic maturation, decreased inhibitory activity onto pyramidal neurons, and impaired synaptic plasticity (30-32). Mouse models of Dup15q suggest similar themes of disruption. For instance, in the Dup15q mouse model with large duplications of the syntenic region, impairments in spine turnover and cerebellar synaptic plasticity have been observed $(33,34)$. However, these cellular phenotypes, 
along with relevant behavioral phenotypes, are only observed in paternal duplication mice, whereas only maternal duplication results in Dup15q in patients (35). In another mouse model, increased levels of $U B E 3 A$ are linked to decreased glutamatergic signaling, suggesting aberrant synaptic activity may be involved in the pathophysiology of Dup15q (36). The maternal inheritance of Dup $15 q$ and the phenotypic overlap with AS strongly implicate $U B E 3 A$ as a causative gene in Dup15q. However, GABAR subunits and other genes linked to neuronal function are duplicated in this region and are probably also involved. The difficulty in developing animal models that accurately mimic large duplications and/ or changes to multiple genes provides a strong argument for the use of human cells with the actual disease-causing mutations for modeling Dup15q and other polygenic syndromes.

\section{Fragile X Syndrome}

Fragile $\mathrm{X}$ syndrome, which is also associated with an autism phenotype, is due to CGG repeat expansion within the FMR1 gene. This results in hypermethylation and therefore FMR1 silencing (37). Animal models and postmortem human nervous tissue have consistently shown abnormal dendritic spine structure and increases in spine number (38). In addition, there may be deficits in GABAergic signaling leading to imbalances in excitatory and inhibitory activity (39). The FMR1 gene encodes a protein (FMRP) that acts as a translational repressor, regulating the translation of many important synaptic proteins at or near dendritic spines (40). For instance, some FMRP target mRNA's include PSD95, Arc, CaMKII, and AMPAR subunit mRNAs (41). Arc and CaMKII have also been tied to UBE3A and AS pathophysiology. These findings suggest aberrant synaptic signaling most likely underlies at least some aspects of FXS.

\section{Rett Syndrome}

Rett syndrome (RTT) - a neurodevelopmental disorder in which affected females develop normally until 1-2 years of age but subsequently show developmental decline, motor abnormalities, and autistic symptoms-is another disorder in which it has been clearly shown that synaptic signaling is abnormal (42). RTT arises from mutations in the $\mathrm{X}$-linked $M E C P 2$ gene, responsible for producing a methyl-CPG-binding protein. This protein controls the expression of many other proteins by binding to their promoters (43). Some examples include BDNF, UBE3A, and GABAB3 (44). $\mathrm{BDNF}$ is important for activity-dependent regulation of dendritic development and synaptic activity and plasticity and BDNF signaling is impaired in AS mice $(45,46)$. UBE3A and GABAB3 are also associated with 15q11-q13 disorders and are core components of synaptic function. MECP2 itself is abundant in neurons, and changes in this protein have been linked to reduced dendritic spine numbers, impaired long-term potentiation (LTP), and decreased excitatory and inhibitory synaptic transmission, deficits that are almost analogous to those identified in FXS models $(47,48)$.

\section{Other ASD-Associated Mutations}

Similar abnormalities have been found in models of TSC, Timothy syndrome (TS), Phelan-McDermid syndrome (PMS) (SHANK3 mutations), and neuroligin and neurexin mutant mice (15). The latter two (neuroligins and neurexins) are genes whose mutations have been identified in patients with ASD (23). Changes in TSC genes lead to changes in dendritic spine length and density as well as synaptic plasticity (49). SHANK3 mutations have been linked to synapse formation and dendritic spine regulation, and mouse models of SHANK3 mutations have ASD-relevant behaviors, including social impairments (50). Neuroligins, which interact with SHANK, and neurexins, have also been linked to ASDrelevant behaviors in mice. Not surprisingly, mutations in these genes lead to disruptions in synaptic transmission.

It is clear from the above discussion of animal models of ASDrelated disorders that abnormal synaptic activity and plasticity are linked to impaired brain function in association with the underlying pathophysiology of these disorders. Due to the difficulty of associating mouse neural development with the appropriate corresponding stages of human neural development, it is less clear when these types of synaptic dysfunction arise in human brain tissue. Again, the possibility also exists that such synaptic changes may be downstream consequences of intrinsic functional changes in neurons or glia at embryonic stages of development, or could represent compensatory homeostatic shifts in response to such primary deficits. For this reason, studying the in vitro development of human neurons harboring disease-causing genetic insults provide us with a richer understanding of the pathophysiology of ASD.

\section{THE PROMISE OF iPSCs FOR MODELING NEURODEVELOPMENTAL DISORDERS}

Although animal models of disease are well suited for the study of monogenetic disorders, many genetic forms of ASD are due to larger deletions or duplications encompassing multiple genes that are not easily modeled in animals. The discovery of iPSC technology and the ability to generate specific subtypes of neurons from patient-derived samples allows for the accurate modeling of these disorders at a genetic level. Furthermore, iPSC models provide a means for identifying physiological deficits in vitro in human neurons roughly equivalent to gestational stages of development, as previously discussed (4) that can lead to synaptic dysfunction in mature neurons. Below we summarize some of the initial work using iPSC-derived neuronal models and the promises they hold for building on in the future.

\section{5q11-q13 Disorders}

As described earlier, AS results from maternal loss of the UBE3A gene, which is paternally silenced in neurons by a long noncoding antisense transcript that is not made on the maternal allele due to methylation. Thus, to accurately model this disorder with iPSC-derived neurons, these neurons would also have to show the appropriate imprinting of this genetic region. In one of the earlier studies of iPSC models of neurodevelopmental disorders, Chamberlain and colleagues derived neurons from subjects with AS and Prader-Willi syndrome (associated with paternal chromosome $15 q$ deletion) (51). They found that correct imprinting occurs during the differentiation of iPSCs into neurons, thus silencing paternal $U B E 3 A$, and neurons from AS subjects are 
missing UBE3A protein. Although it was shown that these neurons were functional, as they fired APs and had synaptic activity, no comparisons were made regarding the electrophysiological phenotypes between patient cell lines and controls. A more recent study, discussed below, has in fact identified functional deficits in neuronal and synaptic maturation in AS neurons (52) and others have further explored AS and PWS-associated imprinting in both iPSC-derived neurons and non-neuronal cells (53-55).

Induced pluripotent stem cell models have also been used to examine changes in gene expression in neurons from patients with either AS (15q11-q13 deletion) or Dup15q, which despite opposite genetic causes, present with overlapping clinical phenotypes. Interestingly, copy number did not consistently predict gene expression levels, and most of the genes that were differentially expressed in both AS and Dup15q neurons compared with controls changed in the same direction (56). A recent follow-up study, also discussed below, has uncovered electrophysiological deficits in Dup 15q neurons that are distinct from the AS neuronal phenotype (57).

\section{Rett Syndrome}

Several studies have developed iPSC-derived neuronal models of Rett syndrome. One of the earliest and most impressive studies capitalized on non-random X-linked inactivation to derive isogenic pairs of neurons from Rett syndrome patients and observed a synaptic deficit as measured by decreases in the number of vGLUT puncta and a decrease in spine density in lines containing the mutation. This morphological deficit was confirmed by electrophysiological recordings, which revealed decreases in both the frequency and amplitude of spontaneous excitatory synaptic currents (58). The synaptic deficit could be rescued by treatment with IGF1, which has been shown to improve RTT-associated behaviors in a mouse model (59). Another study by the same group observed an impairment in the developmental switch from excitatory to inhibitory GABA signaling due to reduced expression of the KCC2 chloride transporter (60). Additional studies of RTT pathophysiology have also used isogenic cell lines. These studies observed a smaller soma size and disruptions in developmental maturation, although this latter conclusion was based on decreases in various neuronal markers as measured by qPCR and immunocytochemistry (61-63).

Similar themes of developmental disruption in vitro have been confirmed in iPSC-derived neuron models with additional RTTand seizure-associated gene mutations including CDLK5 (64-66) and FOXG1 (67). In mouse hippocampal neurons, CDLK5 is localized to excitatory synaptic compartments and is important for dendritic spine function. This was confirmed in human cells as iPSC-derived neurons with CDLK5 mutations had reductions in dendritic spine number (66). The role of GluD1, a glutamate receptor subunit that acts as a synaptic adhesion molecule, has also been examined in RTT-associated MECP2, CDLK5, and FOXG1 mutations $(64,67)$. Changes in GluD1 expression in iPSC-derived neurons were associated with changes in excitatory and inhibitory synapse number as measured by expression levels of synaptic markers; however, synaptic function/dysfunction was not examined electrophysiologically. With regard to electrophysiological characterization, iPSC-derived neurons with MECP2 isoform-specific mutations have significantly increased input resistance and decreased capacitance, consistent with the decreased soma size described above (68). AP firing, voltage-gated sodium and potassium currents, and spontaneous synaptic activity were all altered in MECP2 mutant neurons. Electrophysiological measurements of iPSC-derived neurons from a mouse model of RTT (69) found similar results, with decreases in AP firing and synaptic activity.

Interestingly, both MECP2 duplications as well as deletions result in syndromes with overlapping phenotypes in patients, analogous to the 15q11-q13 region. iPSC-derived neurons from patients with $M E C P 2$ duplications also develop synaptic impairments, but with elevated levels of synaptic markers and increased dendritic complexity as measured by Sholl analysis (70). Network activity monitored by multielectrode arrays (MEAs) also revealed increases in burst activity and neuronal synchrony.

Induced pluripotent stem cell models have also yielded insights into the role of glia in the pathophysiology of neurological disorders. For instance, both RTT mouse astrocytes and RTT iPSC-derived astrocytes have disrupted microtubule transport (71), which has implications for synaptic maintenance and additional astrocyte functions. A non-cell-autonomous role for iPSC-derived astrocytes in RTT has also been established, as either the presence of astrocyte-conditioned media or astrocyte coculture with iPSC-derived neurons negatively impacts neuronal morphology and function, independent of changes to neuronal intrinsic properties, which are also known to contribute to changes in morphology. This suggests distinct mechanisms for morphological changes in neurons (72). This study, however, only provided limited insight into alterations in synaptic function.

\section{Fragile X Syndrome}

A large number of studies have used iPSC-derived neurons to model FXS (4). Most have provided proof-of-concept studies that validate appropriate FMRP1 expression and CGG repeat lengths and focus on the development of various high-throughput assays for rescuing FMR1 expression (73-78). These studies have also confirmed many of the broad phenotypes previously established in mouse models of FXS. For instance, it has been shown that iPSC-derived neurons have disrupted neuronal differentiation, including decreases in both the length and number of neuronal processes $(76,78)$. Gene expression analysis confirmed disruptions in neuronal differentiation as important axon guidance genes such as SLIT and ROBO were significantly decreased in FXS-derived neurons, which was mediated by the REST complex (79). iPSC-derived neurons have also been produced from patients with Fragile X-associated tremor/ataxia, a disorder that results from premutation expansions. Similar to typical FXS, these neurons also have reduced synapse number as measured by loss of PSD95 expression and reduced synaptic puncta, as well as decreased neurite length. These cells also had increased frequencies and amplitudes of calcium transients, suggesting elevated network activity (80).

Unlike with RTT iPSC studies, very little electrophysiology has been used in the study of iPSC-derived FXS neurons, despite the important electrophysiological phenotypes established in the mouse model. In contrast to this, there have been important 
studies using electrophysiological characterization of hESCderived neuron models of FXS. These studies have confirmed similar reductions in neurite number and length as observed in iPSC studies, but have also measured impaired AP firing, showing that FXS neurons have immature APs characterized by small amplitudes and long durations (81). This was reflected by significantly reduced inward sodium currents. Frequency and amplitude of spontaneous synaptic events were also reduced in these cells. GABA receptor physiology has also been studied using electrophysiology by patching neurons and applying GABA locally (82). Two types of responses to GABA puff were observed: (1) a non-desensitizing, bicuculline-sensitive, mature response and (2) a desensitizing, bicuculline-insensitive immature response. Control neurons switched to the more mature response as they developed, whereas FXS neurons showed predominantly immature responses.

\section{Timothy Syndrome}

Timothy syndrome results from mutations to the L-type calcium channel Cav1.2, which makes it a "channelopathy" associated with autism, thus electrophysiological characterization of TS neurons is highly important. Studies on iPSC neurons derived from TS patients observed impaired activity-dependent expression of genes related to ASD and calcium signaling $(83,84)$, as well as reduced expression of upper and lower cortical layer markers. APs and calcium transients also had longer durations, suggesting disrupted calcium channel inactivation. CaMKII, an important synaptic protein involved in LTP, was decreased in TS neurons and has also been linked to disrupted synaptic plasticity in AS mouse models. Primary cortical neurons from TS mice as well as TS iPSC-derived neurons also show disrupted dendritic motility in response to depolarization. Control neurons responded to $\mathrm{KCl}$ with dendritic extension, whereas TS neurons responded to $\mathrm{KCl}$ with dendritic retraction. As $\mathrm{KCl}$ is a manipulation commonly used to mimic "increased activity" in neuronal networks, this suggests TS neurons respond abnormally to changes in neuronal network activity (85).

\section{Other Autism-Associated Mutations}

Disruptions of important synaptic molecules and scaffolding proteins, often associated with ASD and/or neurodevelopmental disorders, also lead to neuronal and synaptic pathophysiology in iPSC-derived neurons. Importantly, many of the papers in this category provide comprehensive electrophysiological characterization including investigation of both intrinsic properties and synaptic activity. First, PMS, caused by loss of the synaptic scaffolding protein SHANK3 has been modeled using both iPSC and hESC-derived neurons. These studies replicated findings of synaptic impairment and increased input resistance in neurons associated with SHANK3 mutations in mouse models. In contrast to the minimal electrophysiology carried out in other iPSC-derived neuron models of disease, these studies examined AP firing, spontaneous synaptic activity, evoked AMPAR and NMDAR responses, and responses to focal AMPAR and NMDAR stimulation, paired with extensive molecular and immunocytochemical characterization. As with RTT, IGF1 treatment could rescue the PMS phenotypes $(86,87)$.
hESC-derived neurons have also been used to study mutations in the synapse-associated proteins syntaxin-binding protein 1 (STXBP1), NRXN1, and L1CAM. STXBP1 is an important presynaptic protein associated with seizures. Mutations to STXBP1 in hESC-derived neurons resulted in significant decreases in spontaneous and evoked synaptic activity due to decreased neurotransmitter release, whereas input resistance, capacitance, and AP firing were unchanged (88). NRXN1 mutations also resulted in significant decreases in synaptic activity despite normal intrinsic properties and normal dendritic morphology and synapse number (89). L1CAM mutations, by contrast, caused significant decreases in axonal length and branching but also dendritic length, dendritic branching, and axon initial segment length. These changes in axon properties were reflected by significantly reduced inward $\mathrm{Na}^{+}$currents and excitability in these cells (90). No changes were observed in number of synaptic puncta, input resistance, or cell capacitance.

Induced pluripotent stem cell-derived neuron models of additional ASD-associated mutations include TRPC6, CHD8, and FOXG1 (91-93). These mutations are associated with changes in gene expression linked to neurite growth, cell adhesion, and neural development $(92,93)$. TRPC6 mutations caused reduced synaptic puncta density and decreased dendritic length and branching. Interestingly, levels of TRPC6 can be changed by MECP2, whose mutation results in strikingly similar dendritic phenotypes, as discussed above. Although electrophysiological properties were not extensively characterized, TRPC6 mutant neurons fired APs and displayed voltage-gated inward and outward currents.

Finally, using a specific endophenotype of macrocephaly to select patients, a recent study uncovered a role for Wnt signaling in the pathophysiology of iPSC-derived neurons from idiopathic ASD patients. This study found changes in gene expression related to sensory perception, but also related to cell adhesion molecules (94). Similarly, patient-derived neurons displayed reduced dendritic branding and synaptic puncta density. Recordings using MEAs revealed decreased spiking and network bursting, which could be rescued by IGF1.

\section{ELECTROPHYSIOLOGICAL ANALYSIS OF IPSC-DERIVED NEURONS}

Several studies have provided extensive electrophysiological characterization of iPSC-derived neurons including addressing issues of variability across cell lines, multiple clonal lines, and differentiations, as well as benchmarks for maturity. These studies have been carried out both in the context of disease modeling but also in control iPSC-derived neurons. Such studies are important as understanding the functional consequence of genetic disruptions on neuronal communication will ultimately better inform our understanding of neural pathophysiology. These papers characterize AP firing, synaptic activity, and sometimes other intrinsic properties during a brief developmental window, usually during early in vitro development, and with limited numbers of lines.

A series of papers has focused on iPSC-derived neurons in relation to alcohol dependence, FKBP5 regulation, and glucocorticoid 
activation (95-97). These cells express voltage-gated inward and outward currents, fire APs in response to current injection, respond to puff application of glutamate and GABA, and display spontaneous synaptic activity. These studies found significant differences in ethanol-induced gene expression in iPSC-derived neurons from controls versus patients with alcohol dependence.

Induced pluripotent stem cell-derived neurons from members of a family with DISC1 mutations, which are associated with psychiatric disorders, found dysregulation of synaptic markers as measured by RNA sequencing as well as significantly reduced synaptic puncta as measured by immunocytochemistry (98). These findings were supported by electrophysiological recordings that showed decreased spontaneous synaptic activity at 4 and 6 weeks in vitro. This synaptic impairment was due to disrupted neurotransmitter release at the presynaptic terminal.

It has been established, using karyotyping and gene expression analysis, that iPSC-derived neurons from trisomy 21 patients, maintain trisomy (99). This genetic disruption was associated with significantly reduced frequencies of spontaneous synaptic activity as measured by electrophysiology. AP firing was not different between controls and patients. Other studies have shown increases in spiking and calcium transients in Williams syndrome-derived neurons complemented by gene expression and morphological studies, and that neurons derived from Alzheimer's patients mature into functional neurons, as measured by the presence of AP firing and synaptic activity, despite the presence of AD cellular pathology $(100,101)$. It should be noted that this latter study did not perform in-depth electrophysiological analysis of genotypic differences. Nonetheless, this investigation provides insight into cellular dysfunction in these diseases that complements the genetic and molecular data provided in these studies.

Other studies have used electrophysiology to uncover cellular phenotypes. For example, patch clamp and MEA studies uncovered a hyperexcitable phenotype in iPSC-derived neurons from ALS patients with SOD1 mutations (102). Hyperexcitability was characterized by increases in both spontaneous and induced AP firing. A significant decrease in the delayed rectifier potassium current was also observed, which supports alterations in AP firing.

Two other studies have provided strong electrophysiological analysis of iPSC-derived neurons from patients with Dravet syndrome. Dravet syndrome is caused by mutations in the SCN1A gene, which codes for the Nav1.1 channel, and patients with these mutations present with intractable epilepsy in childhood. Mutations to Nav1.1 increased sodium current density in both pyramidal and bipolar neurons resulting in enhanced AP firing and burst activity (103). By contrast, a study that derived neurons from twins with Dravet syndrome found that sodium current density and AP firing were reduced in inhibitory neurons and unchanged in excitatory neurons (104).

\section{ELECTROPHYSIOLOGICAL DEVELOPMENT AND MATURATION}

To uncover developmental cellular phenotypes, it is critical to establish protocols for maturation in vitro that produced neurons that express mature AP firing, spontaneous synaptic transmission, and activity-dependent synaptic plasticity. Furthermore, developmental analysis of neuronal function via electrophysiology is required to differentiate early primary insults from homeostatic responses in late in vitro development. Several iPSC-derived neuron studies have examined electrophysiological maturation and benchmarks of maturity across time in culture, as reviewed below:

- Using a protocol designed to generate electrophysiologically mature neurons, $70-80 \%$ of recorded cells fired repetitive APs in response to current injection. Cells had $\sim 1 \mathrm{G} \Omega$ input resistance and $\sim-50$ to $-60 \mathrm{mV}$ RMP (105). AP features include $>60 \mathrm{mV}$ amplitude and a $<3 \mathrm{~ms}$ half-width (HW), indicating mature APs. Greater than $50 \%$ of these cells fired spontaneous APs and $60-80 \%$ of neurons were synaptically active. Frequency of synaptic activity was between 0.5 and $1.5 \mathrm{~Hz}$. Another recent study has performed similar electrophysiological analysis of iPSC-derived neurons (106).

- Another study has shown that input resistances go down with age, while cell capacitance goes up. Neuronal RMP becomes more hyperpolarized ( -45 to -70 by 70 days in culture) and $100 \%$ of neurons firing $>1$ AP by 42 days in culture. AP amplitudes were between 80 and $100 \mathrm{mV}$ and the average $\mathrm{HW}$ was $<3 \mathrm{~ms} .100 \%$ of neurons were synaptically active by $>20$ days in vitro. Frequency of spontaneous synaptic activity reached $\sim 1 \mathrm{~Hz}$ at $>50$ days in vitro. This study also showed responses to AMPA, Kainate, and NMDA application (107).

- With regards to electrophysiological maturation in the context of disease, one study has performed a strong electrophysiological analysis of control neuron maturation as compared with ALS patient-derived neurons (108). Most neurons fired single APs with current injection across development with only $10-15 \%$ of cells showing repetitive firing. In this study, $\sim 20 \%$ show no firing. Although these features were measured over time in culture, little maturation of these features was observed. However, across development, ALS neurons show greater extent of immaturity. About $40 \%$ of control neurons were synaptically active with little to no developmental maturation. Significantly less activity was observed in ALS neurons at later stages in culture. Glutamate, GABA, and glycine application responses were also measured.

- Electrophysiological development of iPSC-derived neurons plated on either laminin or astrocytes for up to 4 months showed maturation of electrophysiological properties over time (109). These included maturation of AP firing as measured by decreased AP HW and increased AP amplitudes as well as a reduction in input resistance, increase in capacitance, and increased intrinsic currents and synaptic event frequency. Increasing dendritic complexity was also observed across time in culture. This maturation was significantly better across all features when iPSC-derived neurons were cultured on astrocytes. For example, synaptic frequency was increased threefold to fourfold. This paper also shows that inhibitory synaptic activity matures more slowly than excitatory synaptic activity and that iPSC-derived neurons can respond to GABA, glutamate, and NMDA application. A more recent study has 
also used astrocyte cocultures to look at glutamatergic and GABAergic neurons to study excitatory/inhibitory balance, which has been shown to be an important role player in autism pathophysiology (110).

- Additional studies have developed a protocol that directly converts fibroblasts into neurons via the overexpression of neural-lineage transcription factors $(111,112)$. These induced neurons fire APs both spontaneously and in response to current injection. The amplitudes of these APs are similar to values described above and the RMP of these cells becomes more hyperpolarized with time in culture. Input resistance decreases from $>1$ G $\Omega$ early in development to less than $500 \mathrm{M} \Omega$ in late development, and capacitance increases over time. APs become more and more repetitive as in vitro development proceeds, and although synaptic development is not as closely studied in this paper, the traces depicted in this study indicate the presence of increased levels of spontaneous synaptic activity.

- Developmental analysis of hESC-derived neurons shows that very young cells during the neuroepithelial rosette stage show increases in $\mathrm{Na}^{+}$current with time in culture, with little change in outward $\mathrm{K}^{+}$currents (113). hESC-derived neurons later in development, however, show decreasing $\mathrm{Na}^{+}$and $\mathrm{K}^{+}$currents, increasing input resistances, and more depolarized RMP across time. They also classify AP firing into four categories ranging from immature passive responses to more mature repetitive firing, and that these neurons are very heterogeneous in their firing, as neighboring neurons often showed very different firing patterns. These findings are the counter to expected results and of those described above.

- A similar study by the same group has been performed on iPSC-derived neurons (114). They classify AP firing into the same four categories and find similar heterogeneity. Although no developmental analysis was done, this study compared a single control line and a single schizophrenia patient line. There were no significant differences between these lines in RMP, inward and outward currents, or input resistance. Input resistance was also much greater than previous studies by other groups (>2.5 G $\Omega$ ) and RMP was much more depolarized (between -20 and $-30 \mathrm{mV}$ ). Importantly for the field, this paper looked at spontaneous electrical activity including AP firing and the presence of UP-states, and later was able to monitor this activity with calcium imaging and correlate single spikes measured with patch clamping with single calcium transient via imaging on the same neuron. As single-cell PCR was performed on each cell, they were also able to screen for genes that correlate with the presence of UP-states.

The above studies have begun to establish a foundation of electrophysiological benchmarks for iPSC-derived neurons and have in some cases uncovered cellular phenotypes related to disease. However, these studies have not been able to measure these features in the context of a more physiological neural environment and generally focus on electrophysiological recordings from individual neurons without addressing synaptic input and network connectivity. Below we address some of the progress relate to these experimental issues.

\section{THE EXPANDING TOOLBOX FOR IPSC- DERIVED NEURONS}

Functional characterization of neurons via electrophysiological analysis is important in light of the fact that neurons communicate via the release of neurotransmitter and AP firing. However, this functional input and output occurs in the context of brain microcircuits composed of distinct and defined cell types which are part of larger brain networks. Disease-induced dysfunction is often due to disruptions of particular cell types within brain circuits and networks. For this reason, it is important to attempt to study iPSC-derived neurons in similar contexts.

To these ends, some early progress has been made. This topic has been reviewed in-depth elsewhere (115), but cell type- and region-specific differentiation protocols are gaining more attention. Such protocols have been used to generate motor neurons (116), dopaminergic neurons (117), GABAergic neurons including specific subtypes (118), serotonergic neurons (119), hippocampal dentate granule neurons (120), and hypothalamic neurons (121). Protocols have also been established for generating astrocytes (122) and microglia (123), glial cell types that play important roles in synaptic development and pruning.

In addition to examining gene and protein expression of cell type-specific markers, several of these studies have undertaken detailed electrophysiological characterization. For example, one study carried out robust electrophysiological characterization of GABAergic neurons including AP firing, synaptic responses, synaptic integration in transplantation studies, and paired this with disease modeling (124). In other studies, iPSC-derived dentate gyrus granule neurons were generated from bipolar disorder (BD), as these cells have been previously tied to BD pathophysiology (125). This paper used a combination of gene expression studies, electrophysiology, and calcium imaging to establish a hyperexcitable phenotype in these neurons. Perhaps the more impressive finding in these studies is that neurons derived from patients who clinically responded to lithium treatment, also showed reduced hyperexcitability with lithium treatment, while non-responding patient neurons also had no response. This was recapitulated in the follow-up study in which DG neurons were generated from a different source of somatic cells from a separate cohort of BD patients (126).

As with animal models, manipulating specific cell types within relevant circuits with optogenetics is a crucial tool for advancing our knowledge of how elements of these circuits work. To this end, various studies have been published recently on optogenetic manipulation of hESC and iPSC-derived neuron activity. For example, a model circuit of motor neuron-to-muscle synapse was used to study Myasthenia Gravis (127), and it was shown that optogenetic stimulation of the motor neuron could result in muscle twitch. Similarly, human stem cell-derived neurons have been transplanted into animal brains where optogenetic stimulation of dopamine neurons was used to study Parkinson's disease (128).

A similar transplantation study of iPSC-derived neurons paired with optogenetic stimulation has been used to study synaptogenesis and synaptic integration (129). These experiments showed that transplanted iPSC-derived neurons have more immature electrophysiological features compared with host cells, including 
slower APs and a more depolarized RMP. In addition, host cells formed limited functional synaptic connections with grafted cells in early development (as measured by optogenetic stimulation of host cells), but this integration increased by 24 weeks post-graft. It has also been shown that AP firing of iPSC-derived neurons can be controlled by optogenetic stimulation (107).

Several recent studies have explored approaches to promote neuronal and synaptic maturation. For example, the culture media most widely used for the maintenance of neuronal cell cultures have been generated to promote cell survival and neuronal differentiation, and it is not clear how well these media support neuron function and maturation of electrophysiological properties. One of the most comprehensive electrophysiological characterizations of iPSC-derived neurons to date found that traditional DMEM/ F12 and Neurobasal media actually impair electrophysiological function and maturation, as measured by AP firing, excitatory and inhibitory synaptic activity, and voltage-gated currents (130). A novel medium was designed that promoted neuron function by eliminating ingredients from traditional media that were found to impair function. Both calcium imaging and MEA recordings were also used in this study to measure network activity of neuronal cultures.

It is clear that many distinct differentiation protocols can generate functionally mature neurons. However, the heterogeneity of neuronal electrical properties remains an issue in the field. To address this, a recent study classified neurons into subtypes via an unbiased statistical analysis of electrophysiological measurements including resting membrane potential, $\mathrm{Na}^{+}$and $\mathrm{K}^{+}$current properties, and AP properties (131). This approach allows the objective study of more homogenous and uniformly mature neurons. Importantly, this study found that the frequency of both spontaneous excitatory and inhibitory synaptic currents was much higher in more mature cells, and that soma size and dendritic complexity were also linearly related to neuronal maturity. Single-cell sequencing revealed that mRNA expression, including transcript levels associated with AP firing, synaptic function, channels, and synaptic receptors, all correlated with electrophysiological maturity. In addition, biomarkers were identified, including GDAP1L1, which predicted functional maturity based on electrophysiological properties.

Despite these early advances, many studies using iPSC-derived neurons lack thorough electrophysiological characterization. The study of actual function in these cells, especially when testing treatments to rescue dysfunction, is of the utmost importance. Thus, electrophysiological analysis must be a main focus of modeling neurological disorders with iPSCs in the future. This next generation of studies should also continue to pair electrophysiological analysis with newer protocols for cell type-specific cultures, as discussed, with combinations of neuronal types and more defined neural circuits. Pairing single-cell electrophysiology at this level with population analysis using calcium imaging or MEAs will also add another layer of understanding to many of these studies.

\section{THE WAY FORWARD}

It is clear that synaptic impairments are a common feature of neurodevelopmental disorders. This pathophysiological hallmark has been observed in numerous mouse models and has been extensively studied using electrophysiology, as understanding the functional outcomes of these changes, especially within physiological neural circuits in the mouse brain, will better inform our understanding of disease. In line with this, we have discussed advances in iPSC-derived neuron technology and how electrophysiology and cell type-specific differentiation protocols are bringing us closer to similar levels of rigor of disease modeling in this new field. However, little work has differentiated whether any of these findings are truly primary disease phenotypes or either downstream or compensatory changes in response to disease. Outside of mouse models, studies of human postmortem brain tissue from ASD patients have reported changes in neuron size and number in various regions of neocortex, including prefrontal cortex, a cortical area important for higher-order cognitive processes including social, emotional, and communicative functions $(132,133)$. Such changes may be the result of deficient activitydependent development of neuronal networks, a process heavily dependent on proper synaptic signaling in early nervous system development. In other words, processes commonly disrupted in mouse models of neurodevelopmental disorders. Thus, an appealing hypothesis for the pathophysiology of autism is one in which deficient spontaneous synaptic and AP firing activity, early in neural development, results in sparser and aberrant connectivity and changes to neuron morphology and neural circuitry. Abnormal connectivity in combination with impaired synaptic plasticity would result in neuronal networks that may insufficiently process synaptic input during activity-dependent synaptic remodeling, a window of development in which sensory input is critical in further developing and refining synaptic connections and neural networks (134). Interestingly, this marks the period of development when autistic features first emerge.

Although it is clear that autism and autism-associated neurodevelopmental disorders can be viewed as disorders of synaptic structure and/or function, this view does not account for heterogeneity between these clinically distinct syndromes, nor does it explain the heterogeneity from patient-to-patient within a single syndrome. In many cases, it is also unclear how synaptic deficits might lead to treatments for each of the specific autismassociated syndromes. This goal requires a better understanding of the primary pathophysiology of these disorders throughout the earlier stages of development before secondary synaptic deficits accumulate.

\section{A NEW PERSPECTIVE FOR UNDERSTANDING SYNAPTIC DEFICITS}

The studies reviewed above indicate widespread synaptic dysfunction among various clinically distinct neurodevelopmental disorders. However, it is not clear whether these synaptic deficits are primary cellular phenotypes directly downstream of genetic/ molecular insults, secondary phenotypes, or the result of compensatory mechanisms in response to primary changes in excitability or network activity. This latter scenario is an interesting hypothesis in light of the limited progress that has been made in translating findings in mouse models to human ASD patients 
(11). As iPSC-derived neurons have been shown to be, at least transcriptionally, equivalent to mid- to late-gestational age, these cells provides a unique opportunity for investigating these important questions.

As described earlier, iPSC-derived neurons have been used to study SHANK3 mutations, which are associated with PMS. The finding that PMS neurons had a significantly elevated input resistance led to a follow-up study to investigate the possible causes for this. Analysis of hESC-derived neurons with either heterozygous or homozygous SHANK3 mutations at $\sim 3$-week in vitro replicated the increased input resistance reported in patient-derived PMS neurons, but also had decreased dendritic complexity, reduced synaptic event amplitudes, and increased AP firing (86). These findings were confirmed in SHANK3 mutant neurons from a mouse model. This change in synaptic activity and AP firing is reminiscent of many functional findings associated with studies of neurological disease, and, on its own, suggests no particular mechanism for separating PMS from other neurological disorders. The increased input resistance suggested decreased channel expression, and further experiments found that the hyperpolarization-activated current (Ih), which plays an important role in regulating neuronal excitability, was greatly diminished in SHANK3 mutant neurons. Moreover, SHANK3 interacts with the HCN channels that mediate Ih, suggesting that SHANK3 may act as a scaffolding protein for these channels. Most importantly, prolonged HCN channel block in control neurons recapitulated the entire spectrum of SHANK3 mutant phenotypes, suggesting that changes in excitability, synaptic activity, and dendritic morphology are either downstream or compensatory effects of HCN channel/Ih reduction (86).

We have recently published a study on the use of iPSCderived neurons to study functional impairments of AS-derived neurons (52). Electrophysiological analysis over 20 weeks in culture revealed maturation of physiological properties including RMP hyperpolarization, increases in AP maturity, decreases in AP duration, increases in both AP amplitude and transient $\mathrm{K}^{+}$ current density, and increases in the frequency of synaptic activity as well as the percent of synaptically active cells. Spontaneous AP activity as assayed by calcium imaging also was present throughout in vitro development in control neurons. These features are more mature than many of those described in the studies above, although these neurons have been cultured for much longer, and are closest to those of iPSC-derived neurons that have been cultured in the presence of astrocytes. Thus, these data provide a robust timeline for electrophysiological maturation of iPSC-derived neurons that could inform future studies.

Compared with control neurons, AS-derived neurons failed to show the same degree of maturation across 20 weeks in culture. AS neurons showed immature resting membrane potentials and firing, and lower levels of synaptic activity. They also had significantly fewer AP-dependent calcium transients. Impaired maturation was seen in neurons derived from large deletion AS patients as well a patient with a mutation to $U B E 3 A$ alone. To further confirm the critical role of $U B E 3 A$ loss, a CRISPRengineered $U B E 3 A$ knockout line recapitulated the entire range of AS developmental phenotypes (52).
It is known from mouse models of AS that there is a critical period (early in development) in which rescue of $U B E 3 A$ can also rescue behavioral phenotypes (135). To determine whether acute $U B E 3 A$ changes cause similar phenotypes, we knocked down (KD) UBE3A using treatment with antisense oligonucleotides against $U B E 3 A$ at early (6-9 weeks in culture) and late (18-20 weeks in culture), which reduced UBE3A message and protein $\sim 50 \%$. While both early and late UBE3A KD in control neurons could recapitulate the depolarization of RMP, only early knockdown could change AP firing and synaptic activity. This prompted us to ask whether or not UBE3A loss results in a primary change to RMP that then drives changes in firing and synaptic activity, as changes in resting potential can disrupt neuronal excitability and function and thus trigger compensatory changes. To test this, we depolarized control neurons with $\mathrm{KCl}$ for the duration of their development followed by electrophysiological analysis. As with AS and UBE3A KD/KO neurons, $\mathrm{KCl}$-treated control neurons displayed the entire spectrum of AS-phenotypes, despite the presence of UBE3A (52).

These phenotypes are not observed in mouse models of AS, although there has been an observation of a hyperpolarized RMP later in development (136). Such differences might be due to the differences in the developmental time periods being studied in mouse models vs iPSC-derived neuronal cultures. Changes in synaptic activity and plasticity commonly observed at mature ages in mouse models of AS may be a consequence of earlier changes in RMP, as suggested in our study. Relevant targets of UBE3A that may relate to changes in synaptic activity and plasticity have been hard to identify. It is known that ubiquitin ligases are expressed in different cell types and change their targets in a brain region- and developmental stage-specific manner (137). Thus, relevant targets of UBE3A may need to be identified during critical developmental periods.

We have also recently characterized genotypic differences between iPSC-derived neurons from Dup15q patients vs. controls subjects (57). In contrast to AS-derived neurons, Dup15q neurons do not show disrupted RMP development, however, AP firing maturation is slightly delayed. These neurons, however, have increased synaptic event frequency and amplitude and disrupted synaptic plasticity, including the inability to scale down AMPAR amplitudes when challenged with increases in network activity by blocking GABARs. This latter plasticity is known as homeostatic synaptic plasticity and is important for maintaining a set point of neuronal firing and its disruption has been linked to neurodevelopmental disorders (138). In line with this, Dup15q neurons have increased spontaneous AP firing and increased synchrony compared with control neurons, as seen by patch clamp recordings and population calcium imaging. Finally, pharmacological screening, flow cytometry, and immunocytochemistry reveal that this excessive firing is due, at least in part, to disruption of seizure-associated KCNQ2 channels.

These results establish three mechanisms of hyperexcitabilty in Dup15q neurons; increased synaptic event frequency and amplitude, impaired synaptic scaling, and increased AP firing due to KCNQ2 disruptions. Although we have not yet differentiated primary vs. secondary phenotypes, it is interesting to speculate that the impaired down-scaling in Dup15q neurons may contribute 
to the development of excessive firing and synchronous activity. Likewise, impaired up-scaling may be occluded by excessive baseline firing. Deficits in KCNQ2 channels may also contribute to synaptic scaling deficits.

As discussed earlier in this review, iPSC-derived neurons from patients with Dravet syndrome express increased sodium current density and increased AP bursting in both pyramidal (excitatory) and bipolar (inhibitory) neurons (103). This phenotype also includes bursting activity in both types of neurons from these patients. Although hyperexcitability in pyramidal neurons would contribute to seizure susceptibility, the same phenotype in presumably inhibitory neurons would inhibit seizure activity. It has also been shown both in human (104) and mouse (139) that sodium currents are actually unchanged in excitatory neurons, and decreased in inhibitory neurons. This net disinhibition is more consistent with seizure activity. Despite these contrasting results, the initial report of paradoxical sodium current density changes were later confirmed in a mouse model at a developmental age that had not been previously investigated (140). Although the combination of these studies does not directly address primary vs. secondary phenotypes, it does suggest the increases in sodium current density observed by Liu et al. and Mistry et al. may actually be the earliest signs of dysfunction that may eventually lead to the contrasting findings reported by other studies.

\section{LIMITATIONS AND FUTURE DIRECTIONS}

Despite their great promise and the important advancements made using iPSC-derived neuron models, the limitations and road blocks that lie ahead are many. These shortcomings have been extensively reviewed elsewhere (141), but there are two specific areas worth discussing further, in light of identifying primary physiological phenotypes in these models: (1) synaptic plasticity and (2) neural circuitry.

Plasticity is the process by which neurons undergo changes in either structure, function, or both, in response to various stimuli including changes in synaptic input and network activity or cellautonomous changes like intrinsic excitability. In line with this broad definition, a large number of functionally distinct types of plasticity have been established and have been reviewed at length (142). Briefly, one broad type of plasticity, activity-dependent plasticity, includes processes that both strengthen and weaken synaptic strength, termed LTP and long-term depression (LTD), respectively. This type of plasticity is important for the proper development and refinement of cortical circuits and is critical to normal brain function. In line with this, it has been well established that disruptions of these types of plasticity are important hallmarks of a broad range of neurological disorders including Alzheimer's disease and schizophrenia, as well as autismassociated neurodevelopmental disorders such as Fragile X, Rett syndrome, Tuberous sclerosis, and AS (15). Although the mechanisms underlying these types of plasticity have been extensively studied in mice, similar types of synaptic plasticity have not been established in iPS-derived neuron models to date. This remains a critical area for further study (143). Despite the lack of reports of synaptic plasticity in stem cell-derived neurons, there have been promising steps forward in a limited number of studies. For example, iPSC-derived neurons cultured on MEAs showed LTP and LTD-like phenomena as measured by changes in spiking activity in response to high frequency stimulation (144). Although these changes occurred in different neurons in response to the same stimulation, these phenomena lasted for at least 1-h post-induction. How this type of plasticity relates to changes in synaptic function or structure was not investigated.

Another common form of plasticity is induced by long-term changes in network activity. Blocking AP firing (with TTX) or increasing AP firing (via GABA block) results in changes to AMPA receptor expression. Such plasticity, termed homeostatic synaptic scaling, has also been demonstrated in neurons derived from a human embryonic stem cell line (145). Deficits in synaptic scaling have been tied to various neurodevelopmental syndromes in mouse models. In a study of Dup $15 q$ using human iPSC-derived neurons, control cells displayed the expected increases and decreases in AMPA event amplitude in response to manipulations in network activity as measured by both immunocytochemistry and electrophysiology. Interestingly, Dup15q neurons were not able to scale AMPA events either up or down, which could contribute to a hyperexcitable phenotype in these cells (57).

Finally, pharmacologically induced plasticity protocols, which have successfully been used in mouse brain slices and cultured neurons to elicit LTP (146), have also been used in studies of iPSC-derived neurons (52). In a study using AS neurons, for example, plasticity induction via pharmacologically increased cAMP levels and enhanced activation of NMDA receptors caused a long-term elevation of spontaneous synaptic event frequency in control neurons which was absent in AS-derived neurons, paralleling LTP deficits in AS mouse models. Similar plasticity deficits were seen in the Dup15q neurons, and in both cases, the deficits in plasticity of synaptic transmission were paralleled by deficits in plasticity of AP firing as revealed by calcium imaging.

As mentioned, synaptic plasticity plays an important role in the function of neuronal circuits in the brain, and many experimental protocols rely on the established circuits of the brain for recording from neurons in a particular area or layer of the brain and stimulating neurons in another area or layer. Another important limitation of typical iPSC-derived neuronal cultures is the lack of a layered cortical structure. Development of 3D culture systems will be important for studying human neurological disorders and for understanding how disease-relevant cellular phenotypes are expressed in an anatomically accurate cortical or hippocampal circuit.

Despite this limitation, progress has been made in recent years in establishing protocols that yield 3D brain-like structures called "organoids" that have generated a proof-of-principle for the in vitro study of important neurodevelopmental processes in models of, for example, ASD (91), lissencephaly (147), microcephaly (148), and ZIKA virus infection (149-151). These advancements have been extensively reviewed elsewhere (152-155). It is worth mentioning, however, that many of these studies, although using different protocols, have shown expression of brain region-specific markers, appropriate layering, interneuron migration, the presence of outer radial glia (an important human 
cell type), migration of cortical neurons, radial organization, presence of active zones, and the presence of many of the correct cell types, including astrocytes. Moreover, many of these papers also pair this characterization with electrophysiological analysis and gene expression analysis, providing a rich data set for identifying underlying disease pathophysiology.

\section{CONCLUSION}

Since the discovery of somatic cell reprogramming and the differentiation of patient-specific neural tissue almost a decade ago, we have come a long way in developing this powerful technology, and the possibilities to use this platform for understanding human disease and developing targeted therapies remains wide open. Despite this, challenges remain and overcoming these obstacles will certainly be a prime focus of investigation moving forward. Although animal models have been important for gaining insight into disease mechanisms and relating disease phenotypes to animal behavior, there has been little translational success of these findings to treatments for human patients. One important issue relates to studying the earliest stages of neural development, to better establish and understand the initiation of pathophysiology without the confounding influences of homeostatic responses and the development of secondary phenotypes. In relation to human tissue, there is great difficulty in assessing primary phenotypes from postmortem brain samples, unhealthy tissue, or tissue collected later in development (156). These specific cases are confounded by compensatory changes of neurons and other cell types to the presence of abnormal tissue or disrupted cell types. Also, these cases miss the period during which synapses

\section{REFERENCES}

1. Pankevich DE, Altevogt BM, Dunlop J, Gage FH, Hyman SE. Improving and accelerating drug development for nervous system disorders. Neuron (2014) 84:546-53. doi:10.1016/j.neuron.2014.10.007

2. Yung JS-Y, Tam PK-H, Ngan ES-W. Pluripotent stem cell for modeling neurological diseases. Exp Cell Res (2012) 319:177-84. doi:10.1016/j. yexcr.2012.11.007

3. Avior Y, Sagi I, Benvenisty N. Pluripotent stem cells in disease modelling and drug discovery. Nat Rev Mol Cell Biol (2016) 17:170-82. doi:10.1038/ nrm.2015.27

4. Ardhanareeswaran K, Mariani J, Coppola G, Abyzov A, Vaccarino FM. Human induced pluripotent stem cells for modelling neurodevelopmental disorders. Nat Rev Neurol (2017) 13:265-78. doi:10.1038/nrneurol. 2017.45

5. Brennand KJ, Simone A, Tran N, Gage FH. Modeling psychiatric disorders at the cellular and network levels. Mol Psychiatry (2012) 17:1239-53. doi: $10.1038 / \mathrm{mp} .2012 .20$

6. Kaiser T, Feng G. Modeling psychiatric disorders for developing effective treatments. Nat Med (2015) 21:979-88. doi:10.1038/nm.3935

7. Takahashi K, Tanabe K, Ohnuki M, Narita M, Ichisaka T, Tomoda K, et al. Induction of pluripotent stem cells from adult human fibroblasts by defined factors. Cell (2007) 131:861-72. doi:10.1016/j.cell.2007.11.019

8. Sheng M, Sabatini BL, Südhof TC. Synapses and Alzheimer's disease. Cold Spring Harb Perspect Biol (2012) 4:a005777. doi:10.1101/cshperspect.a005777

9. Zoghbi HY, Bear MF. Synaptic dysfunction in neurodevelopmental disorders associated with autism and intellectual disabilities. Cold Spring Harb Perspect Biol (2012) 4:a009886. doi:10.1101/cshperspect.a009886

10. Lüscher C, Isaac JT. The synapse: center stage for many brain diseases. J Physiol (2008) 587:727-9. doi:10.1113/jphysiol.2008.167742 are pruned and excessive neurons undergo apoptosis to refine neural circuits.

Another concern, which has also been commented on elsewhere, focuses on the differences in the development of the brain between mice and humans. Such matching of developmental stages is difficult, and studying mouse models at ages which reflect distinct stages of human gestation and brain development is challenging (157). The combination of these situations lends further support to advantages of human stem cell-derived neurons. Regardless of their current limitations, iPSC-derived models provide a unique opportunity to address these important questions. These studies will drive new knowledge as it relates to disease pathophysiology which can be used to further inform experiments using animal models. This will provide a powerful cross-talk between model systems which promises to lead to a much more robust understanding of disease mechanism that can be leveraged to better develop molecular targets for treatment of human disease.

\section{AUTHOR CONTRIBUTIONS}

The first draft was written by JF and subsequently edited and approved for publication by JF and EL.

\section{FUNDING}

Support was provided by NIH Grants NS078753 and MH094896 (EL), the Dup15q Alliance (JF), the Angelman Syndrome Foundation (EL), and the CT Regenerative Medicine Research Fund (EL).
11. Mullins C, Fishell G, Tsien RW. Unifying views of autism spectrum disorders: a consideration of autoregulatory feedback loops. Neuron (2016) 89:1131-56. doi:10.1016/j.neuron.2016.02.017

12. Huguet G, Ey E, Bourgeron T. The genetic landscapes of autism spectrum disorders. Annu Rev Genomics Hum Genet (2013) 14:191-213. doi:10.1146/ annurev-genom-091212-153431

13. Jeste SS, Geschwind DH. Disentangling the heterogeneity of autism spectrum disorder through genetic findings. Nat Rev Neurol (2014) 10:74-81. doi:10.1038/nrneurol.2013.278

14. Christensen DL, Baio J, Van Naarden Braun K, Bilder D, Charles J, Constantino JN, et al. Prevalence and characteristics of autism spectrum disorder among children aged 8 years - autism and developmental disabilities monitoring network, 11 sites, United States, 2012. MMWR Surveill Summ (2016) 65:1-23. doi:10.15585/mmwr.ss6503a1

15. Ebert DH, Greenberg ME. Activity-dependent neuronal signalling and autism spectrum disorder. Nature (2013) 493:327-37. doi:10.1038/nature11860

16. Veenstra-VanderWeele J, Cook EH. Molecular genetics of autism spectrum disorder. Mol Psychiatry (2004) 9:819-32. doi:10.1038/sj.mp.4001505

17. Geschwind DH. Autism: many genes, common pathways? Cell (2008) 135:391-5. doi:10.1016/j.cell.2008.10.016

18. Mitchell KJ. The genetics of neurodevelopmental disease. Curr Opin Neurobiol (2010) 21:197-203. doi:10.1016/j.conb.2010.08.009

19. Hiroi N, Takahashi T, Hishimoto A, Izumi T, Boku S, Hiramoto T. Copy number variation at 22q11.2: from rare variants to common mechanisms of developmental neuropsychiatric disorders. Mol Psychiatry (2013) 18:1153-65. doi:10.1038/mp.2013.92

20. Bourgeron T. A synaptic trek to autism. Curr Opin Neurobiol (2009) 19:231-4. doi:10.1016/j.conb.2009.06.003

21. Jiang Y-H, Ehlers MD. Modeling autism by SHANK gene mutations in mice. Neuron (2013) 78:8-27. doi:10.1016/j.neuron.2013.03.016 
22. Monteiro P, Feng G. SHANK proteins: roles at the synapse and in autism spectrum disorder. Nat Rev Neurosci (2017) 18:147-57. doi:10.1038/nrn. 2016.183

23. Südhof TC. Neuroligins and neurexins link synaptic function to cognitive disease. Nature (2008) 455:903-11. doi:10.1038/nature07456

24. Kalsner L, Chamberlain SJ. Prader-Willi, Angelman, and 15q11-q13 duplication syndromes. Pediatr Clin North Am (2015) 62:587-606. doi:10.1016/j. pcl.2015.03.004

25. Chamberlain SJ, Lalande M. Neurodevelopmental disorders involving genomic imprinting at human chromosome 15q11-q13. Neurobiol Dis (2010) 39:13-20. doi:10.1016/j.nbd.2010.03.011

26. Chamberlain SJ, Lalande M. Angelman syndrome, a genomic imprinting disorder of the brain. JNeurosci (2010) 30:9958-63. doi:10.1523/ JNEUROSCI.1728-10.2010

27. Jiang Y-H, Bressler J, Beaudet AL. Epigenetics and human disease. Annu Rev Genomics Hum Genet (2004) 5:479-510. doi:10.1146/annurev. genom.5.061903.180014

28. Nicholls RD, Knepper JL. Genome organization, function, and imprinting in Prader-Willi and Angelman syndromes. Annu Rev Genomics Hum Genet (2001) 2:153-75. doi:10.1146/annurev.genom.2.1.153

29. Mabb AM, Judson MC, Zylka MJ, Philpot BD. Angelman syndrome: insights into genomic imprinting and neurodevelopmental phenotypes. Trends Neurosci (2011) 34:293-303. doi:10.1016/j.tins.2011.04.001

30. Yashiro K, Riday TT, Condon KH, Roberts AC, Bernardo DR, Prakash R, et al. Ube3a is required for experience-dependent maturation of the neocortex. Nat Neurosci (2009) 12:777-83. doi:10.1038/nn.2327

31. Wallace ML, Burette AC, Weinberg RJ, Philpot BD. Maternal loss of Ube3a produces an excitatory/inhibitory imbalance through neuron type-specific synaptic defects. Neuron (2012) 74:793-800. doi:10.1016/j.neuron. 2012.03.036

32. Judson MC, Wallace ML, Sidorov MS, Burette AC, van Woerden GM, King IF, et al. GABAergic neuron-specific loss of Ube3a causes Angelman syndromelike EEG abnormalities and enhances seizure susceptibility. Neuron (2016) 90:56-69. doi:10.1016/j.neuron.2016.02.040

33. Isshiki M, Tanaka S, Kuriu T, Tabuchi K, Takumi T, Okabe S. Enhanced synapse remodelling as a common phenotype in mouse models of autism. Nat Commun (2014) 5:4742. doi:10.1038/ncomms5742

34. Piochon C, Kloth AD, Grasselli G, Titley HK, Nakayama H, Hashimoto K, et al. Cerebellar plasticity and motor learning deficits in a copy-number variation mouse model of autism. Nat Commun (2014) 5:5586. doi:10.1038/ ncomms 6586

35. Nakatani J, Tamada K, Hatanaka F, Ise S, Ohta H, Inoue K, et al. Abnormal behavior in a chromosome-engineered mouse model for human 15q11-13 duplication seen in autism. Cell (2009) 137:1235-46. doi:10.1016/j.cell. 2009.04.024

36. Smith SEP, Zhou Y-D, Zhang G, Jin Z, Stoppel DC, Anderson MP. Increased gene dosage of Ube3a results in autism traits and decreased glutamate synaptic transmission in mice. Sci Transl Med (2011) 3:103ra97. doi:10.1126/ scitranslmed.3002627

37. Haelterman NA, Yoon WH, Sandoval H, Jaiswal M, Shulman JM, Bellen HJ. A mitocentric view of Parkinson's disease. Annu Rev Neurosci (2014) 37: 137-59. doi:10.1146/annurev-neuro-071013-014317

38. Portera-Cailliau C. Which comes first in fragile X syndrome, dendritic spine dysgenesis or defects in circuit plasticity? Neuroscientist (2011) 18:28-44. doi: $10.1177 / 1073858410395322$

39. D'Hulst C, Kooy RF. The GABAA receptor: a novel target for treatment of fragile X? Trends Neurosci (2007) 30:425-31. doi:10.1016/j.tins.2007. 06.003

40. Peñagarikano O, Mulle JG, Warren ST. The pathophysiology of fragile X syndrome. Annu Rev Genomics Hum Genet (2007) 8:109-29. doi:10.1146/ annurev.genom.8.080706.092249

41. Pfeiffer BE, Huber KM. The state of synapses in fragile $\mathrm{X}$ syndrome. Neuroscientist (2009) 15:549-67. doi:10.1177/1073858409333075

42. Chao H-T, Zoghbi HY, Rosenmund C. MeCP2 controls excitatory synaptic strength by regulating glutamatergic synapse number. Neuron (2007) 56:58-65. doi:10.1016/j.neuron.2007.08.018

43. Bienvenu T, Chelly J. Molecular genetics of Rett syndrome: when DNA methylation goes unrecognized. Nat Rev Genet (2006) 7:415-26. doi:10.1038/ nrg1878
44. Chahrour M, Zoghbi HY. The story of Rett syndrome: from clinic to neurobiology. Neuron (2007) 56:422-37. doi:10.1016/j.neuron.2007.10.001

45. Cao C, Rioult-Pedotti MS, Migani P, Yu CJ, Tiwari R, Parang K, et al. Impairment of TrkB-PSD-95 signaling in Angelman syndrome. PLoS Biol (2013) 11:e1001478. doi:10.1371/journal.pbio.1001478

46. Poo MM. Neurotrophins as synaptic modulators. Nat Rev Neurosci (2001) 2:24-32. doi:10.1038/35049004

47. Guy J, Cheval H, Selfridge J, Bird A. The role of MeCP2 in the brain. Annu Rev Cell Dev Biol (2011) 27:631-52. doi:10.1146/annurev-cellbio-092910154121

48. Verpelli C, Sala C. Molecular and synaptic defects in intellectual disability syndromes. Curr Opin Neurobiol (2012) 22:530-6. doi:10.1016/j. conb.2011.09.007

49. Sahin M. Targeted treatment trials for tuberous sclerosis and autism: no longer a dream. Curr Opin Neurobiol (2012) 22:895-901. doi:10.1016/j. conb.2012.04.008

50. Volk L, Chiu S-L, Sharma K, Huganir RL. Glutamate synapses in human cognitive disorders. Annu Rev Neurosci (2015) 38:127-49. doi:10.1146/ annurev-neuro-071714-033821

51. Chamberlain SJ, Chenb P-F, Ngb KY, Bourgois-Rochab F, Lemtiri-Chlieh F, Levinec ES, et al. Induced pluripotent stem cell models of the genomic imprinting disorders Angelman and Prader-Willi syndromes. Proc Nat Acad Sci U S A (2010) 107:17668-73. doi:10.1073/pnas.1004487107/-/ DCSupplemental/pnas.201004487SI.pdf

52. Fink JJ, Robinson TM, Germain ND, Sirois CL, Bolduc KA, Ward AJ, et al. Disrupted neuronal maturation in Angelman syndrome-derived induced pluripotent stem cells. Nat Commun (2017) 8:15038. doi:10.1038/ ncomms 15038

53. Martins-Taylor K, Hsiao JS, Chen P-F, Glatt-Deeley H, De Smith AJ, Blakemore AIF, et al. Imprinted expression of UBE3A in non-neuronal cells from a Prader-Willi syndrome patient with an atypical deletion. Hum $\mathrm{Mol}$ Genet (2013) 23:2364-73. doi:10.1093/hmg/ddt628

54. Chen P-F, Hsiao JS, Sirois CL, Chamberlain SJ. RBFOX1 and RBFOX2 are dispensable in iPSCs and iPSC-derived neurons and do not contribute to neural-specific paternal UBE3A silencing. Sci Rep (2016) 6:25368. doi:10.1038/srep25368

55. Stanurova J, Neureiter A, Hiber M, de Oliveira Kessler H, Stolp K, Goetzke R, et al. Angelman syndrome-derived neurons display late onset of paternal UBE3A silencing. Sci Rep (2016) 6:30792. doi:10.1038/srep30792

56. Germain ND, Chen P-F, Plocik AM, Glatt-Deeley H, Brown J, Fink JJ, et al. Gene expression analysis of human induced pluripotent stem cell-derived neurons carrying copy number variants of chromosome 15q11-q13.1. Mol Autism (2014) 5:44. doi:10.1186/2040-2392-5-44

57. Fink JJ, Schreiner JD, Bloom JE, Baker DS, Robinson TM, Lieberman R, et al. Hyperexcitable phenotypes in iPSC-derived neurons from patients with 15q11-q13 duplication syndrome, a genetic form of autism. BioRxiv (2018). doi: $10.1101 / 286336$

58. Marchetto MCN, Carromeu C, Acab A, Yu D, Yeo GW, Mu Y, et al. A model for neural development and treatment of Rett syndrome using human induced pluripotent stem cells. Cell (2010) 143:527-39. doi:10.1016/j.cell.2010. 10.016

59. Tropea D, Giacometti E, Wilson NR, Beard C, McCurry C, Fu DD, et al. Partial reversal of Rett syndrome-like symptoms in MeCP2 mutant mice. Proc Natl Acad Sci U S A (2009) 106:2029-34. doi:10.1073/pnas. 0812394106

60. Tang X, Kim J, Zhou L, Wengert E, Zhang L, Wu Z, et al. KCC2 rescues functional deficits in human neurons derived from patients with Rett syndrome. Proc Natl Acad Sci U S A (2016) 113:751-6. doi:10.1073/pnas. 1524013113

61. Kim K-Y, Hysolli E, Park I-H. Neuronal maturation defect in induced pluripotent stem cells from patients with Rett syndrome. Proc Natl Acad Sci U S A (2011) 108:14169-74. doi:10.1073/pnas.1018979108

62. Ananiev G, Williams EC, Li H, Chang Q. Isogenic pairs of wild type and mutant induced pluripotent stem cell (iPSC) lines from Rett syndrome patients as in vitro disease model. PLoS One (2011) 6:e25255. doi:10.1371/ journal.pone.0025255

63. McDonald-McGinn DM, Sullivan KE, Marino B, Philip N, Swillen A, Vorstman JAS, et al. 22q11.2 deletion syndrome. Nat Rev Dis Primers (2015) 1:15071. doi:10.1038/nrdp.2015.71 
64. Livide G, Patriarchi T, Amenduni M, Amabile S, Yasui D, Calcagno E, et al. GluD1 is a common altered player in neuronal differentiation from both MECP2-mutated and CDKL5-mutated iPS cells. Eur J Hum Genet (2014) 23:195-201. doi:10.1038/ejhg.2014.81

65. Amenduni M, De Filippis R, Cheung AYL, Disciglio V, Epistolato MC, Ariani F, et al. iPS cells to model CDKL5-related disorders. Eur J Hum Genet (2011) 19:1246-55. doi:10.1038/ejhg.2011.131

66. Ricciardi S, Ungaro F, Hambrock M, Rademacher N, Stefanelli G, Brambilla D, et al. CDKL5 ensures excitatory synapse stability by reinforcing NGL-1PSD95 interaction in the postsynaptic compartment and is impaired in patient iPSC-derived neurons. Nat Cell Biol (2012) 14:911-23. doi:10.1038/ ncb2566

67. Patriarchi T, Amabile S, Frullanti E, Landucci E, Lo Rizzo C, Ariani F, et al. Imbalance of excitatory/inhibitory synaptic protein expression in iPSCderived neurons from FOXG1 \pm patients and in foxg1 \pm mice. Eur J Hum Genet (2015) 24:871. doi:10.1038/ejhg.2015.216

68. Djuric U, Cheung AYL, Zhang W, Mok RS, Lai W, Piekna A, et al. MECP2e1 isoform mutation affects the form and function of neurons derived from Rett syndrome patient iPS cells. Neurobiol Dis (2015) 76:37-45. doi:10.1016/j. nbd.2015.01.001

69. Farra N, Zhang W-B, Pasceri P, Eubanks JH, Salter MW, Ellis J. Rett syndrome induced pluripotent stem cell-derived neurons reveal novel neurophysiological alterations. Mol Psychiatry (2012) 17:1261-71. doi:10.1038/mp.2011.180

70. Nageshappa S, Carromeu C, Trujillo CA, Mesci P, Espuny-Camacho I, Pasciuto E, et al. Altered neuronal network and rescue in a human MECP2 duplication model. Mol Psychiatry (2015) 21:178-88. doi:10.1038/ mp. 2015.128

71. Delépine C, Meziane H, Nectoux J, Opitz M, Smith AB, Ballatore C, et al. Altered microtubule dynamics and vesicular transport in mouse and human MeCP2-deficient astrocytes. Hum Mol Genet (2015) 25:146-57. doi:10.1093/ $\mathrm{hmg} / \mathrm{ddv} 464$

72. Williams EC, Zhong X, Mohamed A, Li R, Liu Y, Dong Q, et al. Mutant astrocytes differentiated from Rett syndrome patients-specific iPSCs have adverse effects on wild-type neurons. Hum Mol Genet (2014) 23:2968-80. doi:10.1093/hmg/ddu008

73. Kumari D, Swaroop M, Southall N, Huang W, Zheng W, Usdin K. Highthroughput screening to identify compounds that increase fragile $\mathrm{X}$ mental retardation protein expression in neural stem cells differentiated from fragile $\mathrm{X}$ syndrome patient-derived induced pluripotent stem cells. Stem Cells Transl Med (2015) 4:800-8. doi:10.5966/sctm.2014-0278

74. O'Donnell WT, Warren ST. A decade of molecular studies of fragile X syndrome. Annu Rev Neurosci (2002) 25:315-38. doi:10.1146/annurev. neuro.25.112701.142909

75. Park C-Y, Halevy T, Lee DR, Sung JJ, Lee JS, Yanuka O, et al. Reversion of FMR1 methylation and silencing by editing the triplet repeats in fragile X iPSC-derived neurons. Cell Rep (2015) 13:234-41. doi:10.1016/j. celrep.2015.08.084

76. Doers ME, Musser MT, Nichol R, Berndt ER, Baker M, Gomez TM, et al. iPSC-derived forebrain neurons from FXS individuals show defects in initial neurite outgrowth. Stem Cells Dev (2014) 23:1777-87. doi:10.1089/ scd.2014.0030

77. Urbach A, Bar-Nur O, Daley GQ, Benvenisty N. Differential modeling of fragile X syndrome by human embryonic stem cells and induced pluripotent stem cells. Cell Stem Cell (2010) 6:407-11. doi:10.1016/j.stem.2010.04.005

78. Sheridan SD, Theriault KM, Reis SA, Zhou F, Madison JM, Daheron L, et al. Epigenetic characterization of the FMR1 gene and aberrant neurodevelopment in human induced pluripotent stem cell models of fragile X syndrome. PLoS One (2011) 6:e26203. doi:10.1371/journal.pone.0026203

79. Halevy T, Czech C, Benvenisty N. Molecular mechanisms regulating the defects in fragile $\mathrm{X}$ syndrome neurons derived from human pluripotent stem cells. Stem Cell Reports (2014) 4:37-46. doi:10.1016/j.stemcr.2014. 10.015

80. Liu J, Koscielska KA, Cao Z, Hulsizer S, Grace N, Mitchell G, et al. Signaling defects in iPSC-derived fragile X premutation neurons. Hum Mol Genet (2012) 21:3795-805. doi:10.1093/hmg/dds207

81. Telias M, Kuznitsov-Yanovsky L, Segal M, Ben-Yosef D. Functional deficiencies in fragile $\mathrm{X}$ neurons derived from human embryonic stem cells. J Neurosci (2015) 35:15295-306. doi:10.1523/JNEUROSCI.0317-15.2015
82. Telias M, Segal M, Ben-Yosef D. Immature responses to GABA in fragile $\mathrm{X}$ neurons derived from human embryonic stem cells. Front Cell Neurosci (2016) 10:121. doi:10.3389/fncel.2016.00121

83. Tian Y, Voineagu I, Pașca SP, Won H, Chandran V, Horvath S, et al. Alteration in basal and depolarization induced transcriptional network in iPSC derived neurons from Timothy syndrome. Genome Med (2014) 6:75. doi:10.1186/ s13073-014-0075-5

84. Paşca SP, Portmann T, Voineagu I, Yazawa M, Shcheglovitov A, Paşca AM, et al. Using iPSC-derived neurons to uncover cellular phenotypes associated with Timothy syndrome. Nat Med (2011) 17:1657-62. doi:10.1038/ nm.2576

85. KreyJF, Paşca SP, Shcheglovitov A, Yazawa M, Schwemberger R, Rasmusson R, et al. Timothy syndrome is associated with activity-dependent dendritic retraction in rodent and human neurons. Nat Neurosci (2013) 16:201-9. doi:10.1038/nn.3307

86. Yi F, Danko T, Botelho SC, Patzke C, Pak C, Wernig M, et al. Autismassociated SHANK3 haploinsufficiency causes Ih channelopathy in human neurons. Science (2016) 352:aaf2669. doi:10.1126/science.aaf2669

87. Shcheglovitov A, Shcheglovitova O, Yazawa M, Portmann T, Shu R, Sebastiano V, et al. SHANK3 and IGF1 restore synaptic deficits in neurons from 22q13 deletion syndrome patients. Nature (2013) 503:267-71. doi:10.1038/nature12618

88. Patzke C, Han Y, Covy J, Yi F, Maxeiner S, Wernig M, et al. Analysis of conditional heterozygous STXBP1 mutations in human neurons. J Clin Invest (2015) 125:3560-71. doi:10.1172/JCI78612

89. Pak C, Danko T, Zhang Y, Aoto J, Anderson G, Maxeiner S, et al. Human neuropsychiatric disease modeling using conditional deletion reveals synaptic transmission defects caused by heterozygous mutations in NRXN1. Cell Stem Cell (2015) 17:316-28. doi:10.1016/j.stem.2015.07.017

90. Patzke C, Acuna C, Giam LR, Wernig M, Südhof TC. Conditional deletion of L1CAM in human neurons impairs both axonal and dendritic arborization and action potential generation. J Exp Med (2016) 213:499. doi:10.1084/ jem.20150951

91. Mariani J, Coppola G, Zhang P, Abyzov A, Provini L, Tomasini L, et al FOXG1-dependent dysregulation of GABA/glutamate neuron differentiation in autism spectrum disorders. Cell (2015) 162:375-90. doi:10.1016/j. cell.2015.06.034

92. Wang P, Lin M, Pedrosa E, Hrabovsky A, Zhang Z, Guo W, et al. CRISPR/ Cas9-mediated heterozygous knockout of the autism gene CHD8 and characterization of its transcriptional networks in neurodevelopment. $\mathrm{Mol}$ Autism (2015) 6:55. doi:10.1186/s13229-015-0048-6

93. Griesi-Oliveira K, Acab A, Gupta AR, Sunaga DY, Chailangkarn T, Nicol X, et al. Modeling non-syndromic autism and the impact of TRPC6 disruption in human neurons. Mol Psychiatry (2014) 20:1350-65. doi:10.1038/ mp.2014.141

94. Marchetto MC, Muotri AR, Belinson H, Tian Y, Freitas BC, Fu C, et al. Altered proliferation and networks in neural cells derived from idiopathic autistic individuals. Mol Psychiatry (2016) 22:820-35. doi:10.1038/mp. 2016.95

95. Lieberman R, Levine ES, Kranzler HR, Abreu C, Covault J. Pilot study of iPS-derived neural cells to examine biologic effects of alcohol on human neurons in vitro. Alcohol Clin Exp Res (2012) 36:1678-87. doi:10.1111/ j.1530-0277.2012.01792.x

96. Lieberman R, Kranzler HR, Joshi P, Shin D-G, Covault J. GABRA2 alcohol dependence risk allele is associated with reduced expression of chromosome 4p12 GABAA subunit genes in human neural cultures. Alcohol Clin Exp Res (2015) 39:1654-64. doi:10.1111/acer.12807

97. Lieberman R, Kranzler HR, Levine ES, Covault J. Examining FKBP5 mRNA expression in human iPSC-derived neural cells. Psychiatry Res (2016) 247:172-81. doi:10.1016/j.psychres.2016.11.027

98. Wen Z, Nguyen HN, Guo Z, Lalli MA, Wang X, Su Y, et al. Synaptic dysregulation in a human iPS cell model of mental disorders. Nature (2014) 515:414-8. doi:10.1038/nature13716

99. Weick JP, Held DL, Bonadurer GF, Doers ME, Liu Y, Maguire C, et al. Deficits in human trisomy 21 iPSCs and neurons. Proc Natl Acad Sci U S A (2013) 110:9962-7. doi:10.1073/pnas.1216575110

100. Chailangkarn T, Trujillo CA, Freitas BC, Hrvoj-Mihic B, Herai RH, Yu DX, et al. A human neurodevelopmental model for Williams syndrome. Nature (2016) 536:338-43. doi:10.1038/nature 19067 
101. Shi Y, Kirwan P, Smith J, MacLean G, Orkin SH, Livesey FJ. A human stem cell model of early Alzheimer's disease pathology in Down syndrome. Sci Transl Med (2012) 4:124ra29. doi:10.1126/scitranslmed.3003771

102. Kiskinis E, Joung JK, Sandoe J, Woolf CJ, Williams LA, Brown RH, et al. Pathways disrupted in human ALS motor neurons identified through genetic correction of mutant SOD1. Cell Stem Cell (2014) 14:781-95. doi:10.1016/j. stem.2014.03.004

103. Liu Y, Lopez-Santiago LF, Yuan Y, Jones JM, Zhang H, O’Malley HA, et al. Dravet syndrome patient-derived neurons suggest a novel epilepsy mechanism. Ann Neurol (2013) 74:128-39. doi:10.1002/ana.23897

104. Sun Y, Paşca SP, Portmann T, Goold C, Worringer KA, Guan W, et al. A deleterious Nav1.1 mutation selectively impairs telencephalic inhibitory neurons derived from Dravet syndrome patients. Elife (2016) 5:e13073. doi:10.7554/eLife.13073

105. Gunhanlar N, Shpak G, van der Kroeg M, Gouty-Colomer LA, Munshi ST, Lendemeijer B, et al. A simplified protocol for differentiation of electrophysiologically mature neuronal networks from human induced pluripotent stem cells. Mol Psychiatry (2017). doi:10.1038/mp.2017.56

106. Kang S, Chen X, Gong S, Yu P, Yau S, Su Z, et al. Characteristic analyses of a neural differentiation model from iPSC-derived neuron according to morphology, physiology, and global gene expression pattern. Sci Rep (2017) 7:12233. doi:10.1038/s41598-017-12452-x

107. Lam RS, Töpfer FM, Wood PG, Busskamp V, Bamberg E. Functional maturation of human stem cell-derived neurons in long-term cultures. PLoS One (2017) 12:e0169506. doi:10.1371/journal.pone.0169506

108. Devlin A-C, Burr K, Borooah S, Foster JD, Cleary EM, Geti I, et al. Human iPSC-derived motoneurons harbouring TARDBP or C9ORF72 ALS mutations are dysfunctional despite maintaining viability. Nat Commun (2015) 6:5999. doi:10.1038/ncomms6999

109. Tang X, Zhou L, Wagner AM, Marchetto MCN, Muotri AR, Gage FH, et al. Astroglial cells regulate the developmental timeline of human neurons differentiated from induced pluripotent stem cells. Stem Cell Res (2013) 11:743-57. doi:10.1016/j.scr.2013.05.002

110. Nadadhur AG, Melero JE, Meijer M, Schut D, Jacobs G, Li KW, et al. Multilevel characterization of balanced inhibitory-excitatory cortical neuron network derived from human pluripotent stem cells. PLoS One (2017) 12:e0178533. doi:10.1371/journal.pone.0178533

111. Vierbuchen T, Ostermeier A, Pang ZP, Kokubu Y, Südhof TC, Wernig M. Direct conversion of fibroblasts to functional neurons by defined factors. Nature (2010) 463:1035-41. doi:10.1038/nature08797

112. Chanda S, Ang CE, Davila J, Pak C, Mall M, Lee QY, et al. Generation of induced neuronal cells by the single reprogramming factor ASCL1. Stem Cell Reports (2014) 3:282-96. doi:10.1016/j.stemcr.2014.05.020

113. Belinsky GS, Moore AR, Short SM, Rich MT, Antic SD. Physiological properties of neurons derived from human embryonic stem cells using a dibutyryl cyclic AMP-based protocol. Stem Cells Dev (2011) 20:1733-46. doi:10.1089/ scd.2010.0501

114. Belinsky GS, Rich MT, Sirois CL, Short SM, Pedrosa E, Lachman HM, et al. Patch-clamp recordings and calcium imaging followed by single-cell PCR reveal the developmental profile of 13 genes in iPSC-derived human neurons. Stem Cell Res (2010) 12:101-18. doi:10.1016/j.scr.2013. 09.014

115. Mertens J, Marchetto MC, Bardy C, Gage FH. Evaluating cell reprogramming, differentiation and conversion technologies in neuroscience. Nat Rev Neurosci (2016) 17:424-37. doi:10.1038/nrn.2016.46

116. Intoh A, Suzuki N, Koszka K, Eggan K. SLC52A3, A Brown-Vialetto-van Laere syndrome candidate gene is essential for mouse development, but dispensable for motor neuron differentiation. Hum Mol Genet (2016) 25:1814-23. doi:10.1093/hmg/ddw053

117. Sánchez-Danés A, Richaud-Patin Y, Carballo-Carbajal I, Jiménez-Delgado S, Caig C, Mora S, et al. Disease-specific phenotypes in dopamine neurons from human iPS-based models of genetic and sporadic Parkinson's disease. EMBO Mol Med (2012) 4:380-95. doi:10.1002/emmm.201200215

118. Yang N, Chanda S, Marro S, Ng YH, Janas JA, Haag D, et al. Generation of pure GABAergic neurons by transcription factor programming. Nat Methods (2017) 14:621-8. doi:10.1038/nmeth.4291

119. Vadodaria KC, Mertens J, Paquola A, Bardy C, Li X, Jappelli R, et al. Generation of functional human serotonergic neurons from fibroblasts. Mol Psychiatry (2015) 21:49-61. doi:10.1038/mp.2015.161
120. Yu DX, Di Giorgio FP, Yao J, Marchetto MC, Brennand K, Wright R, et al. Modeling hippocampal neurogenesis using human pluripotent stem cells. Stem Cell Reports (2014) 2:295-310. doi:10.1016/j.stemcr.2014.01.009

121. Merkle FT, Maroof A, Wataya T, Sasai Y, Studer L, Eggan K, et al. Generation of neuropeptidergic hypothalamic neurons from human pluripotent stem cells. Development (2015) 142:633-43. doi:10.1242/dev.117978

122. Juopperi TA, Kim WR, Chiang C-H, Yu H, Margolis RL, Ross CA, et al. Astrocytes generated from patient induced pluripotent stem cells recapitulate features of Huntington's disease patient cells. Mol Brain (2012) 5:17. doi:10.1186/1756-6606-5-17

123. Abud EM, Ramirez RN, Martinez ES, Healy LM, Newman SA, Yeromin AV, et al. iPSC-derived human microglia-like cells to study neurological diseases. Neuron (2017) 94:278-93.e9. doi:10.1016/j.neuron.2017.03.042

124. Maisano X, Litvina E, Tagliatela S, Aaron GB, Grabel LB, Naegele JR. Differentiation and functional incorporation of embryonic stem cell-derived GABAergic interneurons in the dentate gyrus of mice with temporal lobe epilepsy. J Neurosci (2012) 32:46-61. doi:10.1523/JNEUROSCI.2683-11.2012

125. Mertens J, Wang Q-W, Kim Y, Yu DX, Pham S, Yang B, et al. Differential responses to lithium in hyperexcitable neurons from patients with bipolar disorder. Nature (2015) 527:95-9. doi:10.1038/nature15526

126. Stern S, Santos R, Marchetto MC, Mendes APD, Rouleau GA, Biesmans S, et al. Neurons derived from patients with bipolar disorder divide into intrinsically different sub-populations of neurons, predicting the patients responsiveness to lithium. Mol Psychiatry (2017). doi:10.1038/mp.2016.260

127. Steinbeck JA, Jaiswal MK, Calder EL, Kishinevsky S, Weishaupt A, Toyka KV, et al. Functional connectivity under optogenetic control allows modeling of human neuromuscular disease. Cell Stem Cell (2015) 18:134-43. doi:10.1016/j.stem.2015.10.002

128. Steinbeck JA, Choi SJ, Mrejeru A, Ganat Y, Deisseroth K, Sulzer D, et al Optogenetics enables functional analysis of human embryonic stem cellderived grafts in a Parkinson's disease model. Nat Biotechnol (2015) 33:204-9. doi:10.1038/nbt.3124

129. Avaliani N, Sørensen AT, Ledri M, Bengzon J, Koch P, Brüstle O, et al. Optogenetics reveal delayed afferent synaptogenesis on grafted humaninduced pluripotent stem cell-derived neural progenitors. Stem Cells (2014) 32:3088-98. doi:10.1002/stem.1823

130. Bardy C, van den Hurk M, Eames T, Marchand C, Hernandez RV, Kellogg M, et al. Neuronal medium that supports basic synaptic functions and activity of human neurons in vitro. Proc Natl Acad Sci U S A (2015) 112:E2725-34. doi:10.1073/pnas.1504393112

131. Bardy C, van den Hurk M, Kakaradov B, Erwin JA, Jaeger BN, Hernandez RV, et al. Predicting the functional states of human iPSC-derived neurons with single-cell RNA-seq and electrophysiology. Mol Psychiatry (2016) 21:1573-88. doi:10.1038/mp.2016.158

132. Stoner R, Chow ML, Boyle MP, Sunkin SM, Mouton PR, Roy S, et al. Patches of disorganization in the neocortex of children with autism. $N$ Engl J Med (2014) 370:1209-19. doi:10.1056/NEJMoa1307491

133. Courchesne E, Mouton PR, Calhoun ME, Semendeferi K, Ahrens-Barbeau C, Hallet MJ, et al. Neuron number and size in prefrontal cortex of children with autism. JAMA (2011) 306:2001-10. doi:10.1001/jama.2011.1638

134. West AE, Greenberg ME. Neuronal activity-regulated gene transcription in synapse development and cognitive function. Cold Spring Harb Perspect Biol (2011) 3:a005744. doi:10.1101/cshperspect.a005744

135. Silva-Santos S, van Woerden GM, Bruinsma CF, Mientjes E, Jolfaei MA, Distel B, et al. Ube3a reinstatement identifies distinct developmental windows in a murine Angelman syndrome model. J Clin Invest (2015) 125: 2069-76. doi:10.1172/JCI80554

136. Kaphzan H, Buffington SA, Jung JI, Rasband MN, Klann E. Alterations in intrinsic membrane properties and the axon initial segment in a mouse model of Angelman syndrome. J Neurosci (2011) 31:17637-48. doi:10.1523/ JNEUROSCI.4162-11.2011

137. Mabb AM, Ehlers MD. Ubiquitination in postsynaptic function and plasticity. Annu Rev Cell Dev Biol (2010) 26:179-210. doi:10.1146/ annurev-cellbio-100109-104129

138. Turrigiano G. Homeostatic synaptic plasticity: local and global mechanisms for stabilizing neuronal function. Cold Spring Harb Perspect Biol (2012) 4:a005736. doi:10.1101/cshperspect.a005736

139. Yu FH, Mantegazza M, Westenbroek RE, Robbins CA, Kalume F, Burton KA, et al. Reduced sodium current in GABAergic interneurons in a mouse model 
of severe myoclonic epilepsy in infancy. Nat Neurosci (2006) 9:1142-9. doi:10.1038/nn1754

140. Mistry AM, Thompson CH, Miller AR, Vanoye CG, George AL, Kearney JA. Strain- and age-dependent hippocampal neuron sodium currents correlate with epilepsy severity in Dravet syndrome mice. Neurobiol Dis (2014) 65:1-11. doi:10.1016/j.nbd.2014.01.006

141. Onder TT, Daley GQ. New lessons learned from disease modeling with induced pluripotent stem cells. Curr Opin Genet Dev (2012) 22:500-8. doi:10.1016/j.gde.2012.05.005

142. Malenka RC, Bear MF. LTP and LTD: an embarrassment of riches. Neuron (2004) 44:5-21. doi:10.1016/j.neuron.2004.09.012

143. Chinchalongporn V, Koppensteiner P, Prè D, Thangnipon W, Bilo L, Arancio O. Connectivity and circuitry in a dish versus in a brain. Alzheimers Res Ther (2015) 7:44. doi:10.1186/s13195-015-0129-y

144. Odawara A, Katoh H, Matsuda N, Suzuki I. Induction of long-term potentiation and depression phenomena in human induced pluripotent stem cellderived cortical neurons. Biochem Biophys Res Commun (2015) 469:856-62. doi:10.1016/j.bbrc.2015.12.087

145. Xu J-C, Fan J, Wang X, Eacker SM, Kam T-I, Chen L, et al. Cultured networks of excitatory projection neurons and inhibitory interneurons for studying human cortical neurotoxicity. Sci Transl Med (2016) 8:333ra48. doi:10.1126/ scitranslmed.aad0623

146. Otmakhov N, Khibnik L, Otmakhova N, Carpenter S, Riahi S, Asrican B, et al. Forskolin-induced LTP in the CA1 hippocampal region is NMDA receptor dependent. J Neurophysiol (2003) 91:1955-62. doi:10.1152/jn.00941.2003

147. Bershteyn M, Nowakowski TJ, Pollen AA, Di Lullo E, Nene A, WynshawBoris A, et al. Human iPSC-derived cerebral organoids model cellular features of lissencephaly and reveal prolonged mitosis of outer radial Glia. Cell Stem Cell (2017) 20:435-49.e4. doi:10.1016/j.stem.2016.12.007

148. Lancaster MA, Renner M, Martin C-A, Wenzel D, Bicknell LS, Hurles ME, et al. Cerebral organoids model human brain development and microcephaly. Nature (2013) 501:373-9. doi:10.1038/nature12517

149. Wells MF, Salick MR, Wiskow O, Ho DJ, Worringer KA, Ihry RJ, et al. Genetic ablation of AXL does not protect human neural progenitor cells and cerebral organoids from zika virus infection. Cell Stem Cell (2016) 19:703-8. doi:10.1016/j.stem.2016.11.011
150. Qian X, Nguyen HN, Song MM, Hadiono C, Ogden SC, Hammack C, et al. Brain-region-specific organoids using mini-bioreactors for modeling ZIKV exposure. Cell (2016) 165:1238-54. doi:10.1016/j.cell.2016.04.032

151. Watanabe M, Buth JE, Vishlaghi N, de la Torre-Ubieta L, Taxidis J, Khakh BS, et al. Self-organized cerebral organoids with human-specific features predict effective drugs to combat zika virus infection. Cell Rep (2017) 21:517-32. doi:10.1016/j.celrep.2017.09.047

152. Bershteyn M, Kriegstein AR. Cerebral organoids in a dish: progress and prospects. Cell (2013) 155:19-20. doi:10.1016/j.cell.2013.09.010

153. Lancaster MA, Knoblich JA. Organogenesis in a dish: modeling development and disease using organoid technologies. Science (2014) 345:1247125. doi:10.1126/science. 1247125

154. Arber C, Lovejoy C, Wray S. Stem cell models of Alzheimer's disease: progress and challenges. Alzheimers Res Ther (2017) 9:42. doi:10.1186/ s13195-017-0268-4

155. Quadrato G, Brown J, Arlotta P. The promises and challenges of human brain organoids as models of neuropsychiatric disease. Nat Med (2016) 22:1220-8. doi:10.1038/nm.4214

156. Young-Pearse TL, Morrow EM. Modeling developmental neuropsychiatric disorders with iPSC technology: challenges and opportunities. Curr Opin Neurobiol (2015) 36:66-73. doi:10.1016/j.conb.2015.10.006

157. Parent JM, Anderson SA. Reprogramming patient-derived cells to study the epilepsies. Nat Neurosci (2015) 18:360-6. doi:10.1038/nn.3944

Conflict of Interest Statement: The authors declare that the research was conducted in the absence of any commercial or financial relationships that could be construed as a potential conflict of interest.

Copyright (c) 2018 Fink and Levine. This is an open-access article distributed under the terms of the Creative Commons Attribution License (CC BY). The use, distribution or reproduction in other forums is permitted, provided the original author(s) and the copyright owner are credited and that the original publication in this journal is cited, in accordance with accepted academic practice. No use, distribution or reproduction is permitted which does not comply with these terms. 